\title{
Education and Trade Attitudes: Revisiting the Role of Economic Interest
}

\author{
Yannick Stiller (D), Andreas Dür* (D) and Robert A. Huber (10) \\ University of Salzburg, Salzburg, Austria \\ ${ }^{\star}$ Corresponding author. Email: andreas.duer@plus.ac.at
}

(Received 28 March 2021; accepted 19 November 2021; first published online 8 February 2022)

\begin{abstract}
Why are highly educated people more supportive of international trade? Two competing explanations exist for this empirical finding. On the one hand, the economic interest approach suggests that the highly educated realize that trade can benefit them economically. On the other hand, the ideational perspective argues that this relationship arises because highly educated people are more cosmopolitan, and cosmopolitanism is positively related to support for trade. To contribute to this debate on the education-trade attitude nexus, we present and empirically test four hypotheses. Using data from the PEW Global Attitudes survey (2014) for 36 countries at various levels of development, we find that as expected by the economic interest approach, the effect of education on people's perceptions of the consequences of trade is conditional on respondents' individual and subnational economic context. The results thus show that economic interest at least partly explains education's effects on public opinion towards trade. Beyond adding to this specific debate, the research note makes several broader contributions to research on trade and public opinion.
\end{abstract}

Keywords: Trade attitudes; public opinion; education; economic interest

\section{Introduction}

That education affects individuals' attitudes towards trade is among the most well-established findings in the literature on public opinion and trade attitudes (O'Rourke and Sinnott, 2001; Scheve and Slaughter, 2001; Kaltenthaler et al., 2004; Hainmueller and Hiscox, 2006). Highly educated people, and especially people with university education, are more likely to view trade positively. Initially, studies argued that this is so because highly educated people can expect greater economic benefits from trade (O'Rourke and Sinnott, 2001; Scheve and Slaughter, 2001; Mayda and Rodrik, 2005; Fordham and Kleinberg, 2012). Following this argument, which we call the economic interest perspective, highly educated citizens' support for trade reflects their material interest. Increasingly, however, this view has been contested by scholars who argue that education has an influence on trade attitudes via people's ideas. According to this ideational explanation, education may make people more cosmopolitan and hence more supportive of international trade (Kaltenthaler et al., 2004; Mansfield and Mutz, 2009).

This research note contributes to this debate on the education-trade attitude nexus both theoretically and empirically. With respect to theory, basically all cross-national studies of trade attitudes assume that in developing countries, trade should mainly benefit the less educated (e.g. O'Rourke and Sinnott, 2001; Mayda and Rodrik, 2005; Margalit, 2012). However, recent economic research (i.e. the 'new new trade theory') convincingly shows that even in less developed countries, the more educated are likely to gain more from international trade than the less educated (Burstein and Vogel, 2017; Helpman et al., 2017; Lee, 2020). For example, Burstein

(C) The Author(s), 2022. Published by Cambridge University Press. This is an Open Access article, distributed under the terms of the Creative Commons Attribution licence (https://creativecommons.org/licenses/by/4.0/), which permits unrestricted re-use, distribution, and reproduction in any medium, provided the original work is properly cited. 
and Vogel $(2017,1400)$ conclude that 'gains from trade are larger for skilled than for unskilled workers in most countries'. According to this argument, a positive correlation between education and trade support in poorer countries does not cast doubt on the economic interest perspective any longer. To overcome the resulting observational equivalence between the two approaches, we propose several novel tests for the economic interest perspective. These tests rely on the idea that to the extent economic interests are relevant, the effect of education on trade attitudes should be conditional on individual and subnational economic circumstances.

On the empirical side, we make two contributions. On the one hand, the existing literature finds it difficult to control for the economic context in which individuals make up their minds on whether to support trade. Some studies look at the level of development of a country to capture this context (e.g. Mayda and Rodrik, 2005; Hainmueller and Hiscox, 2006). By contrast, we start from the observation that the economic context may differ strongly across subnational regions within countries, meaning that also the effects of trade may differ across them (for an approach looking at 'microregions', see Campello and Urdinez, 2021). Illustratively, the difference between the most and the least developed regions in Brazil in terms of the human development index (HDI) is approximately equivalent to the difference between Norway (leading all countries in terms of HDI) and Bahrain (number 45 in terms of HDI in the world in 2019). We therefore utilize subnational rather than national data to capture the economic context of respondents. To do so, we use existing data on subnational region's level of development (Smits and Permanyer, 2019) and collected original data on the trade competitiveness of regions across many countries in the world. On the other hand, so far research has given little consideration to people's views concerning the consequences of trade. By contrast, we start from the expectation that these views are important to answer the question why the highly educated are more supportive of trade (see also Rho and Tomz, 2017, S103). We thus formulate expectations about how education should matter for beliefs concerning the effects of trade on jobs and wages rather than for trade support more generally.

We rely on data from the PEW Research Center's Spring 2014 Global Attitudes survey (Pew Research Center, 2014), which was carried out across a large number of countries at different levels of development, in our empirical analysis. The findings of our analysis demonstrate that economic interest plays a role in linking education to perceptions of the consequences of trade. Concretely, the effect of education on perceptions of the consequences of trade on jobs and wages is conditional on economic circumstances at both the individual level and the regional level, as expected by the economic interest perspective. This does not mean that the positive relationship between education and trade support is only a consequence of economic interest. Clearly, there are also aspects of public opinion towards trade that are best explained by the ideational perspective. Rather, we interpret the empirical evidence that we put forward in this research note as suggestive of the complementary role of economic interest. Moreover, the understanding of economic interest that we employ here allows for the possibility that people consider indirect benefits or losses from trade (which could lead to 'sociotropic' attitudes, see Schaffer and Spilker, 2019). For example, a person employed in the public health sector may not directly benefit from trade, but might indirectly if trade increases the standard of living in the area in which she lives.

The relevance of our research note is not limited to speaking to the specific debate about the link between education and trade attitudes. It also contributes to an important, ongoing debate in the field of International Relations on the extent to which models that assume that actors hold preferences in line with their material interests can explain international relations (Lake, 2009; Oatley, 2011; Hafner-Burton et al., 2017). Revisiting the question of how education matters for trade attitudes also is of current interest because, in many countries, trade policy is of high public salience as witnessed by the role it plays in elections (Autor et al., 2020). Moreover, public opinion towards trade policy does not exist in a vacuum; in democracies at least, it can influence decision makers in setting policy outcomes such as tariff levels (Kono, 2008). For an understanding of contemporary politics, it is thus important to know to what extent the politicization of trade policy is driven by economic concerns on the one hand and ideas on the other. 


\section{State of the Art}

Nearly all scholars who have analyzed trade attitudes of citizens over the last few decades have found consistent evidence for the strong predictive power of education. Higher education goes hand-in-hand with greater support for trade. The literature offers two explanations for this link between education and trade attitudes. The first, and chronologically older, perspective which we denote as the economic interest argument - argues that more highly educated people are more supportive of trade because they can expect to materially benefit from it (O'Rourke and Sinnott, 2001; Scheve and Slaughter, 2001; Mayda and Rodrik, 2005; Fordham and Kleinberg, 2012). In this view, which builds on the Stolper-Samuelson theorem, education is a key part of a person's skill set that determines whether an individual benefits or loses from trade liberalization. Since trade increases demand for highly educated workers, the highly educated can expect economic gains from trade. They hence have material reasons to support trade liberalization.

The second explanation comes in two variants: the cosmopolitan ideas variant and the learning-to-love-globalization variant. The former expects that education makes it more likely that an individual holds cosmopolitan world-views (Kaltenthaler et al., 2004; Strijbis et al., 2019). The high support of the educated for trade can thus be explained by their cosmopolitanism, which makes them welcome new products and interactions with other countries. The flipside of this argument is that across countries, the less educated are more likely to hold nationalist sentiments (Coenders and Scheepers, 2003) and that nationalist attitudes reduce support for trade liberalization (O’Rourke and Sinnott, 2001; Mayda and Rodrik, 2005). Following this line of reasoning, Mansfield and Mutz (2009) argue that the effect of education is a result of a person's anxiety about out-groups. Because less educated citizens are more likely to fear immigrants or the influx of foreign culture, they are more likely to oppose trade liberalization. In this vein, Margalit (2012) argues that opposition to trade can be better explained by perceived cultural threats resulting from globalization than by economic threats. Again, the highly educated feel less threatened by cultural inflows or even welcome them, which in turn explains why they tend to support trade liberalization.

The second variant argues that people attending tertiary education 'learn to love globalization' through exposure to the teachings of economic theories that stipulate that free trade maximizes the wealth of a country under most circumstances (Hainmueller and Hiscox, 2006). Even if not all university students attend economics courses, they might have social contacts with students of economics. They are thus more likely to be informed about the postulated efficiency gains of expanded trade, which explains their increased support for trade liberalization. Burgoon and Hiscox (2004) build on this argument and explain the persistent gender gap in trade support (women tend to be more protectionist than men) with the fact that women are less likely to attend economics classes, which reduces their exposure to economic theories about the benefits of trade.

Disentangling to what extent education affects trade attitudes via economic interest or ideas is difficult for several reasons. Basically, both explanations expect the same positive effect of education on trade attitudes. The debate also cannot simply be resolved by adding controls for individuals' ideas - e.g. a measure of individuals' cosmopolitanism - in a regression model explaining trade attitudes, as economic considerations can also influence people's broader values and beliefs (Carreras et al., 2019). Neither do findings that individuals lack knowledge about the economic consequences of trade (Rho and Tomz, 2017) per se invalidate the economic interest explanation. There can be many channels through which individuals develop attitudes that are in line with their economic interests, even if they themselves have little economic knowledge (Fordham and Kleinberg, 2012).

Still, several studies have tried to disentangle the effects of education on trade attitudes, using a variety of tests and approaches (Hainmueller and Hiscox, 2006; Margalit, 2012; van der Waal and 
de Koster, 2015). In general, this literature has concluded that education matters mainly via the ideational channel. Hainmueller and Hiscox (2006) arrive at this finding by comparing the attitudes of people still active in the labor force and people already retired. They only find an effect for college-level education and not for other types of education regardless of the employment status - in essence supporting an ideational perspective. Margalit (2012) uses a survey experiment to show that as cultural concerns become more important, less-well educated people (but not better educated people) become more skeptical of trade. Finally, van der Waal and de Koster (2015) regress support for trade openness on education and several indicators of economic interest, showing that the economic variables can only explain a small share of the overall effect of education.

\section{Education, Context, and Perceptions of the Consequences of Trade}

Our approach at uncovering through which causal mechanism education matters for trade attitudes complements this existing research. We start from the basic point that, even based on new new trade theory, the economic effects of trade on the highly and less educated vary by economic context. As a result, the effect of education on trade attitudes should also depend on context, if the economic interest argument applies. In the following, we develop four hypotheses that relate education and economic context to perceptions concerning the consequences of trade for jobs and wages. To the extent that we find support for these expectations, we can conclude that the economic interest approach retains explanatory power for public opinion towards trade. If we find no or only scant support for these expectations, the conclusion is that the effect of education on trade attitudes mainly works via ideas.

We focus on perceptions of trade's consequences rather than trade support per se because doing so allows us to better understand the drivers of public opinion towards trade. Most people tend to indicate that they broadly support trade and even free trade agreements. Illustratively, according to the PEW data we use in this research note, almost $85 \%$ of respondents think that trade is good or very good for their country. In a survey for the British Department for International Trade (2019), only 3\% of respondents indicated that they somewhat or strongly oppose free trade agreements (Department for International Trade, 2019). We see these strong approval rates as an indication that these questions are too broad to elicit a reasoned response. In other words, rather than conclude that people do not have a more differentiated view of trade, it is plausible that these broad questions simply do not motivate people to express such a view. Questions about respondents' perceptions of the consequences of trade then help to better capture public opinion towards trade. In fact, in the PEW survey we find much more variation for these questions: $56 \%$ of the respondents believe that trade creates jobs, whereas $25 \%$ believe that trade leads to job losses and $20 \%$ think that trade makes no difference in terms of jobs. Moving to perceptions of trade's effect on wages, $45 \%$ of the respondents believe that wages increase as a function of trade. $27 \%$ state that wages decrease due to trade, and another $27 \%$ do not think that wages change because of trade. Disentangling these perceptions about the consequences of trade from the broader policy preferences hence is essential for a better understanding of trade attitudes (see also Rho and Tomz, 2017, S103).

\subsection{Individual-Level Context Factors}

Recent research has shown that across countries, international trade mainly benefits workers with higher education (Burstein and Vogel, 2017; Helpman et al., 2017; Lee, 2020). The higher educated hence should perceive greater benefits from trade for jobs and wages. The economic interest approach, however, also leads to the expectation that this effect is conditional on economic circumstances at the individual and the region level. At the individual-level, a person's employment status should moderate the effect of education on perceptions of the consequences of trade. 
Controlling for age, the difference between highly and less educated respondents should be larger among those respondents that currently are employed (see also Hainmueller and Hiscox, 2006, 476). They can expect to benefit from rising wages first. Those unemployed, by contrast, either do not look for a new job (e.g. because they are retired) or are unlikely to benefit from an increase in jobs and wages (such as the long-term unemployed), independent of their level of education. They are thus less likely to perceive any positive effects of trade on wages or jobs. In other words, if the economic interest approach is correct, employment status should moderate education's effect in shaping peoples' views on the consequences of trade.

H1: The positive effect of education on perceptions of the consequences of trade for jobs and wages is more pronounced for respondents that are currently employed.

The effect of education on perceptions of the consequences of trade should also vary by age. In the economic interest explanation, people do not simply derive their views on trade from their general ideological outlook. Neither do they take their attitudes entirely from what they learn at university. Instead, they derive them from trade's actual economic costs and benefits, either for them directly or for their communities. Doing so requires a certain amount of information and knowledge (Rho and Tomz, 2017). Even controlling for education, not all people can be expected to fulfill this condition, with some being more economically ignorant than others. A variable that likely influences how much information people have about the consequences of trade is age. Older respondents are more likely to have experienced the consequences of increased or decreased trade. They also have had more chances to interact with people that are more knowledgeable than themselves about the topic of trade. The expectation hence is for older respondents to have attitudes that are more in line with their economic interests - meaning that the highly educated have increasingly positive views on the consequences of trade and the less educated increasingly negative views.

$\mathrm{H} 2$ : The positive effect of education on perceptions of the consequences of trade for jobs and wages is more pronounced for older respondents.

Age, of course, also has other potential effects on trade attitudes. To the extent that older people generally are less cosmopolitan, the positive effect of education on trade support should decline with age. Moreover, with older people often no longer employed, their economic interests may be less dependent on trade's effects on jobs and wages. These alternative effects of age should partly offset the expectation formulated in $\mathrm{H} 2$. Any support that we find for $\mathrm{H} 2$ hence should be a conservative estimate.

\subsection{Region-Level Context Factors}

According to the economic interest approach, the effect of education is also moderated by economic circumstances in the region in which a person lives. We focus on two such moderators: level of development and subnational trade competitiveness. Starting with level of development, recent economic research indicates that the higher educated should gain most from trade at all levels of development (Burstein and Vogel, 2017; Helpman et al., 2017; Lee, 2020). This result emerges when allowing for firms to be more or less productive within the same sector.

Nevertheless, the effect size of education should be larger in highly developed regions, because firms from these regions mainly export capital-intensive goods and services, meaning that trade creates especially large demand for highly educated workers. Simultaneously, these regions tend to import labor-intensive goods and services, which leads to lower domestic demand for less educated workers. In less developed regions, this effect is less pronounced. The expectation hence is for trade to have a particularly large effect on the relative demand for highly and less-educated workers in highly developed regions. In these regions, the less educated can expect trade to result 
in fewer jobs and lower wages. Even after accounting for recent developments in the theory of international trade, this expectation is largely in line with the classic Stolper-Samuelson theorem, which anticipates that trade liberalization helps the owners of the relatively abundant factor of production and hurts the relatively scarce factor.

H3: The positive effect of education on perceptions of the consequences of trade for jobs and wages is more pronounced in highly developed regions.

Finally, recent trade theory predicts that only the most competitive firms can reap the benefits of trade liberalization (Melitz, 2003; Bernard et al., 2009). These firms are also more likely to employ highly educated workers (Ciuriak et al., 2015). Indeed, having a large share of highly skilled employees is likely to be an important reason for their high productivity. Education thus should positively correlate with perceptions of the consequences of trade. Competitive firms, moreover, are largely concentrated in regions that exhibit high trade competitiveness, where trade competitiveness means that the region's economic structure is aligned with the country's comparative advantage. In regions with higher trade competitiveness, therefore, the highly educated are likely to benefit even more from trade than in less competitive regions. ${ }^{1}$ In turn, as a region's trade competitiveness increases, the views of the highly educated should become increasingly positive with respect to the consequences of trade. Less educated people's perceptions of the consequences of trade, by contrast, should be largely independent of the region's trade competitiveness. In less competitive regions, they suffer from import competition, but in more competitive regions, the gains from trade mainly go to the more highly educated.

H4: The positive effect of education on perceptions of the consequences of trade on jobs and wages is more pronounced in regions with higher trade competitiveness.

\section{Research Design}

\subsection{Case Selection}

We rely on data collected by the PEW Research Center's Spring 2014 Global Attitudes survey to test the expectations set out above (Pew Research Center, 2014). ${ }^{2}$ This dataset has two major advantages compared to alternatives. First, it includes questions capturing perceptions of the distributional consequences of trade, which help us to better analyze individuals' motives to support and oppose trade. Second, the survey was conducted in 44 countries across the globe. We use 36 of these countries because we lack data of acceptable quality for one of our key predictors for eight countries (see Table A2 in the Appendix). This sample includes countries across all levels of development, which reduces the chance of idiosyncratic findings and allows us to generalize our analyses. It also ensures that we have ample variation with respect to economic context in the dataset, thus allowing us to test our expectations.

\subsection{Measurement}

We measure 'perceptions of the consequences of trade for jobs and wages' relying on two question on whether respondents believe that trade (a) leads to job creation, does not affect jobs, or leads to job losses and (b) increases wages, does not affect wages, or decreases wages. We code

\footnotetext{
${ }^{1}$ Note that 'trade competitiveness' is not a synonym for highly developed. Some regions are highly developed but little competitive in international trade; others are less developed but highly competitive on world markets. In fact, in our dataset the variables capturing regions' economic development and regions' international trade competitiveness are only weakly positively correlated with each other.

${ }^{2}$ Data and replication scripts are available from the Harvard Dataverse: https://doi.org/10.7910/DVN/QHEBXD.
} 
both as ordinal variables with the positive levels (job creation and increases wages) as the highest categories. Section A2 in the Appendix provides the exact wording for all survey questions used in our study.

Following our theoretical argument, we focus on one core predictor (education) and four potential moderators (employment status, age, regional levels of development, and trade competitiveness). Starting with education, we recode country-specific education questions into a variable with two categories: respondents with tertiary education and others. By doing so, we make our results comparable to those reported by Hainmueller and Hiscox (2006). The share of respondents with tertiary education massively varies by country. For example, in Tanzania only $2.5 \%$ attended a university or similar. On the other end of the scale, $45.3 \%$ of US American respondents received tertiary education.

We measure the individual level moderators - employment status (H1) and age (H2) - using standard questions that can be found in subsection A2 of the Appendix. Employment status takes the value ' 1 ' for those in paid work or apprenticeships. Others are coded as not employed (' 0 '). As regards age, we regroup the variable in three categories: young $($ age $\leq 40)$, middle $(40<$ age $\leq 65)$, and old $(65<$ age $)$ respondents.

In order to test Hypothesis 3, we measure level of development using the gross national income per capita (in thousands of USD [2011 PPP]) of the respondents' home regions from Smits and Permanyer (2019). We apply the natural logarithm to this variable. The poorest region in our database is Kolda (Senegal) whereas the richest region is Hamburg (Germany). For the trade competitiveness of regions, which is the predictor in Hypothesis 4, we rely on an approach described in detail in Huber et al. (2021). This subnational trade competitiveness measure captures the extent to which a region aligns with the country's comparative advantage. To operationalize this variable, we use trade data at the national level and employment shares by industry at the regional level (from labour surveys). The trade data allow us to calculate a country's (revealed) comparative advantage based on an approach originally suggested by Vollrath (1991, 275; see RCA 9); and the employment shares allow us to estimate to which extent a region's economic structure aligns with the countries' comparative advantage (see Table A2 in the Appendix for all sources used for the calculation of this variable). This variable is distributed between \pm 2 , with competitive regions having positive values and non-competitive regions negative values. As this measure only compares regions within a country, below we use country-fixed effects.

\subsection{Control Variables and Estimation Strategy}

We control for two characteristics of individual respondents. For one, we include gender in our models as this variable has received much attention in the literature. While the causal mechanism is still contested, numerous studies have found stark differences between men and women when it comes to trade attitudes (Burgoon and Hiscox, 2004; Mansfield et al., 2015). Moreover, we control for individuals' economic left-right self-placement. Finally, we include country-fixed effects to control for country-level influences on trade attitudes. Section A3 in the Appendix provides descriptive statistics for all variables. Given the ordinal nature of our two dependent variables, we rely on ordinal regression. We cluster standard errors at the regional level to account for the regional level predictors. We first estimate coefficients in an additive model before interacting all four moderators and education simultaneously to test Hypotheses 1-4.

\section{Results}

We start by showing that the earlier finding that education and trade attitudes are positively correlated also extends to the perceived consequences of trade on jobs and wages. Next, we test the four hypotheses set out above with the aim of seeing to which extent economic interest can 
explain these correlations. Finally, we link back our findings concerning perceptions of the consequences of trade to trade support.

\subsection{Education and the Perceived Consequences of Trade}

Table 1 presents the regression results for the tests that scrutinize the main effect of education on the perception that trade creates jobs and increases wages. In line with existing research, we find that individuals with tertiary education systematically have a more positive view of trade. Tertiary education is positively correlated with the perceptions that trade creates jobs and leads to higher wages. In terms of the substantive effect size, ceteris paribus, highly educated individuals are $27 \%$ more likely to believe trade creates jobs than other respondents. For wages, this effect is smaller and approximately $8 \%$ in size.

Among the individual-level control variables, especially the respondents' economic left-right position is strongly associated with their perception of the consequences of trade. Women believe that trade has more negative consequences, which is in line with existing research (see, e.g. Burgoon and Hiscox, 2004; Mansfield et al., 2015). With regards to contextual region-level control variables, the level of development is related to negative perceptions.

\subsection{The Conditional Impact of Education on Perceptions of the Consequences of Trade}

As outlined above, the economic interest approach leads to the expectation that economic context moderates the relationship between education and the perceived consequences of trade. In the following, we test the four hypotheses that we derive from this argument by adding interaction terms between education on the one hand, and employment status, age, the region's level of development, and the region's level of competitiveness on the other hand. We again run two models, one each for perceptions of trade on jobs and wages (see the results in Table 2). Starting with Hypothesis 1 and the moderating effect of employment status, the respective coefficient is positive and statistically significant in both models. Figure 1 shows the effect graphically and reveals that our finding is broadly in line with our expectation. In the left panel, which shows the predicted probability to believe trade has positive effects on jobs, we find that the difference between tertiary (turquoise triangles) and non-tertiary (red dots) educated respondents is larger among respondents who are in employment. Concretely, support for the statement that trade induces job creation is approximately three percentage points higher for the tertiary educated among respondents not currently in employment. This increases to more than six percentage points for those currently employed.

The right panel shows the effect of education on perceptions for wages. Here, the differences between the tertiary and non-tertiary educated are smaller. The coefficient of the interaction effect is statistically significant. Hence, we see a trend in the direction expected in H1. While highly educated, unemployed respondents are approximately one percentage point less likely to believe that trade increases wages than the less educated, unemployed respondents, this pattern reverses for employed respondents, where highly educated employed individuals are approximately two percentage points more likely to hold this positive view. Overall, this evidence provides partial support for Hypothesis 1 .

Figure 2 follows Figure 1 in style and shows the predicted probability to hold positive beliefs about trade consequences by education and age. In line with the statistically significant coefficients for this interaction in Table 2, the slopes for the tertiary and non-tertiary educated differ, particularly for jobs. Among young individuals (below 40 years of age), tertiary and non-tertiary educated respondents largely coincide in their perceptions of the consequences of trade for jobs. In contrast, we observe a substantial gap of around 10 percentage points among the oldest respondents (above 65 years of age). For the perception that trade increases wages, the overall pattern is similar, but less pronounced. Among young respondents, the educated tend to be 
Table 1. Education and the perceived consequences of trade

\begin{tabular}{lcc}
\hline & Jobs & Wages \\
\hline Education (Tertiary) & $0.24(0.04)^{\star \star \star}$ & $0.07(0.04)^{\star \star}$ \\
\hline Employment (Employed) & $0.06(0.03)^{\star \star}$ & $-0.02(0.03)$ \\
\hline Age (41-65) & $0.00(0.03)$ & $-0.03(0.03)$ \\
Age (66+) & $0.08(0.06)$ & $0.04(0.05)$ \\
Logged Regional GNIpc & $-0.20(0.10)^{\star}$ & $-0.29(0.08)^{\star \star \star}$ \\
Subnational Trade Competitiveness & $-0.01(0.03)$ & $0.01(0.03)$ \\
Economic Left-Right & $0.21(0.02)^{\star \star *}$ & $0.21(0.02)^{\star \star \star}$ \\
Gender (Female) & $-0.13(0.03)^{\star \star \star}$ & $-0.12(0.02)^{\star \star \star}$ \\
AIC & 59265.20 & 63105.55 \\
Deviance & 59175.20 & 63015.55 \\
N & 31957 & 31358 \\
\hline
\end{tabular}

Notes: ${ }^{\star \star \star} p<0.01,{ }^{\star \star} p<0.05,{ }^{\star} p<0.1$. Entries are unstandardized coefficients from an ordinal logistic regression. Standard errors (in parentheses) are clustered at the region level. Country-fixed effects are omitted from the table.

Table 2. Education, economic context, and perceptions of the consequences of trade

\begin{tabular}{|c|c|c|}
\hline & Jobs & Wages \\
\hline Education (Tertiary) & $-0.22(0.12)^{\star}$ & $-0.41(0.12)^{\star \star \star}$ \\
\hline Employment (Employed) & $0.04(0.03)$ & $-0.05(0.03)$ \\
\hline Education $\times$ Employment & $0.13(0.07)^{\star \star}$ & $0.13(0.06)^{\star \star}$ \\
\hline Age (41-65) & $-0.05(0.03)$ & $-0.07(0.03)^{\star \star}$ \\
\hline Age $(66+)$ & $0.02(0.06)$ & $-0.00(0.05)$ \\
\hline Education $\times$ Age $(41-65)$ & $0.25(0.06)^{\star \star \star}$ & $0.20(0.06)^{\star \star \star}$ \\
\hline Education $\times$ Age $(65+)$ & $0.37(0.11)^{\star \star \star}$ & $0.29(0.11)^{\star \star \star}$ \\
\hline Logged Regional GNIpc & $-0.22(0.10)^{\star \star}$ & $-0.31(0.08)^{\star \star \star}$ \\
\hline Education $\times$ Logged Regional GNIpc & $0.11(0.04)^{\star \star \star}$ & $0.12(0.04)^{\star \star \star}$ \\
\hline Subnational Trade Competitiveness & $-0.02(0.03)$ & $0.00(0.03)$ \\
\hline Education $\times$ Subnational Trade Competitiveness & $0.13(0.03)^{\star \star \star}$ & $0.09(0.03)^{\star \star \star}$ \\
\hline Economic Left-Right & $0.21(0.02)^{\star \star \star}$ & $0.20(0.02)^{\star \star \star}$ \\
\hline Gender (Female) & $-0.13(0.03)^{\star \star \star}$ & $-0.12(0.02)^{\star \star \star}$ \\
\hline $\mathrm{AIC}$ & 59209.07 & 63066.31 \\
\hline Deviance & 59109.07 & 62966.31 \\
\hline $\mathrm{N}$ & 31957 & 31358 \\
\hline
\end{tabular}

Notes: ${ }^{\star \star \star} p<0.01,{ }^{\star \star} p<0.05,{ }^{\star} p<0.1$. Entries are unstandardized coefficients from an ordered logistic regression. Standard errors (in parentheses) are clustered at the region level. Country-fixed effects are omitted from the table.

more skeptical about the positive effect of trade on wages. While tertiary educated individuals are increasingly likely to perceive that trade increases wages as they get older, we see no such effect for the non-tertiary educated. These findings are particularly remarkable because, as discussed above, one could also expect the differences between the more and the less educated to decline for older 


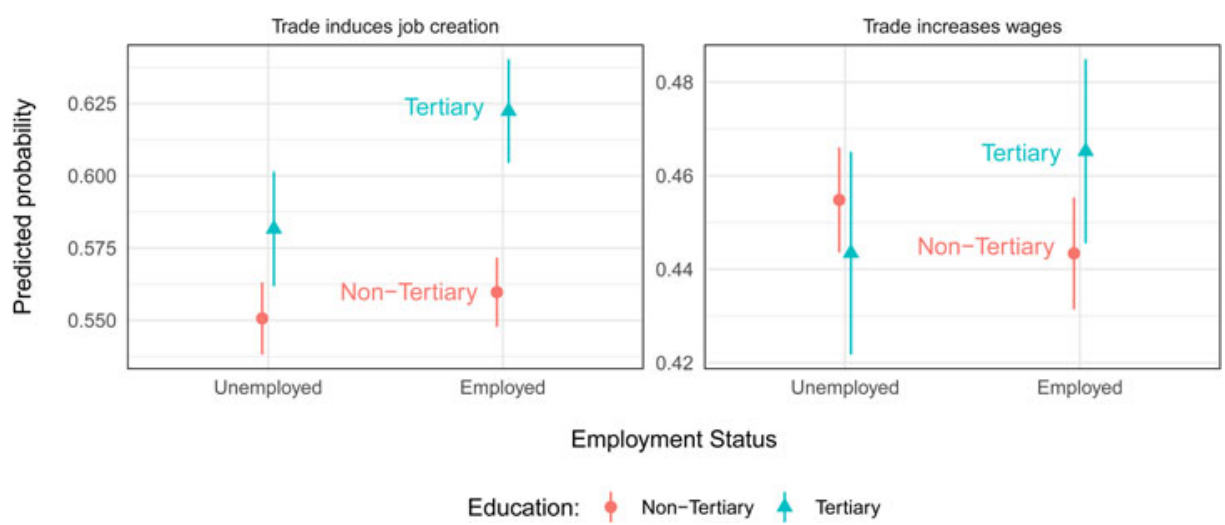

Figure 1. Education, employment status, and perceived consequences of trade Notes: Predicted values stem from the respective models shown in Table 2. Standard errors are clustered at the regional level. Ranges show $90 \%$ confidence intervals. Figures A6 and A7 in the Appendix show the predictions for all outcome categories.

people. Overall, these findings thus offer considerable support for the expectation outlined in Hypothesis 2.

The models in Table 2 include two more moderators at the level of the region in which respondents live. Looking first at the region's level of development, we expect the effect of education to be larger in highly developed regions (H3). The empirical evidence presented is largely consistent with this argument. In Table 2, the respective coefficients are positive and statistically significant. Indeed, in Figure 3, the marginal positive effect of education becomes larger as the region becomes more economically developed. We observe no difference in perceptions of job creation between tertiary and non-tertiary educated individuals in regions with lower levels of development. With increasing development, the differences between the two education groups increases. For wages, we observe that the perception that trade increases wages sharply declines with development. However, this is less pronounced among tertiary educated individuals, again leading to the expected effect of education having a stronger positive effect in higher developed regions. Overall, the evidence thus supports Hypothesis 3.

Interestingly, Figure 3 suggests that citizens become more skeptical of the consequences of trade as the region's level of development increases. This pattern is consistent with the Stolper-Samuelson theorem, but only in less developed countries. In these countries, the regions with the highest GNI often face import-competition from both higher (capital-intensive goods and services) and less developed areas (labour-intensive goods and services). People from the regions hence can be expected to be more skeptical of trade. To see whether this can account for the negative slope in Figure 3, we split our sample at the mean level of development among countries (which is close to 13,000 US\$ GDP per capita). Figures A14 and A15 in the Appendix indeed show that the downwards trend in the belief that trade is beneficial for jobs and wages is only visible for countries at lower levels of economic development. For respondents in countries with higher levels of development, we find a modest upwards slope, meaning that in these countries respondents from more developed regions are slightly more positive about the consequences of trade. Beyond explaining the trends we see in Figure 3, this evidence is highly suggestive of the role of economic interests in public opinion towards trade.

Finally, we expect the effect of education to vary by a region's level of trade competitiveness because trade competitiveness affects the demand for highly and less educated workers. Again, the respective coefficients are positive and statistically significant in Table 2. Figure 4 shows the predictions that result from these coefficients. The findings are perfectly in line with our expectation. Individuals without tertiary education remain largely unaffected by the region's 


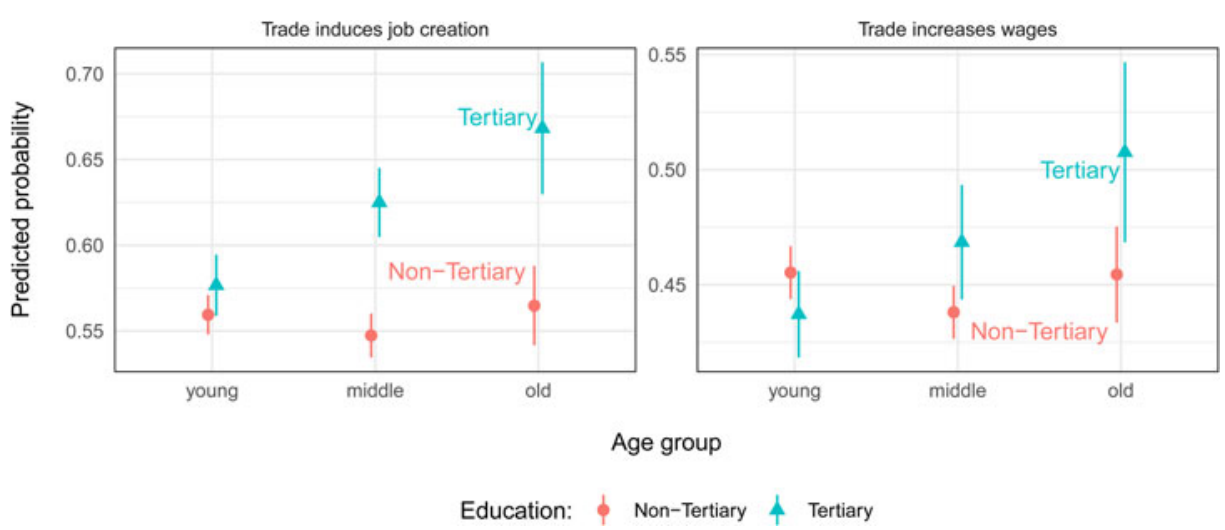

Figure 2. Education, age groups, and perceived consequences of trade

Notes: Predicted values stem from the respective models shown in Table 2. Standard errors are clustered at the region level. Ranges show $90 \%$ confidence intervals. Figures A8 and A9 in the Appendix show the predictions for all outcome categories.

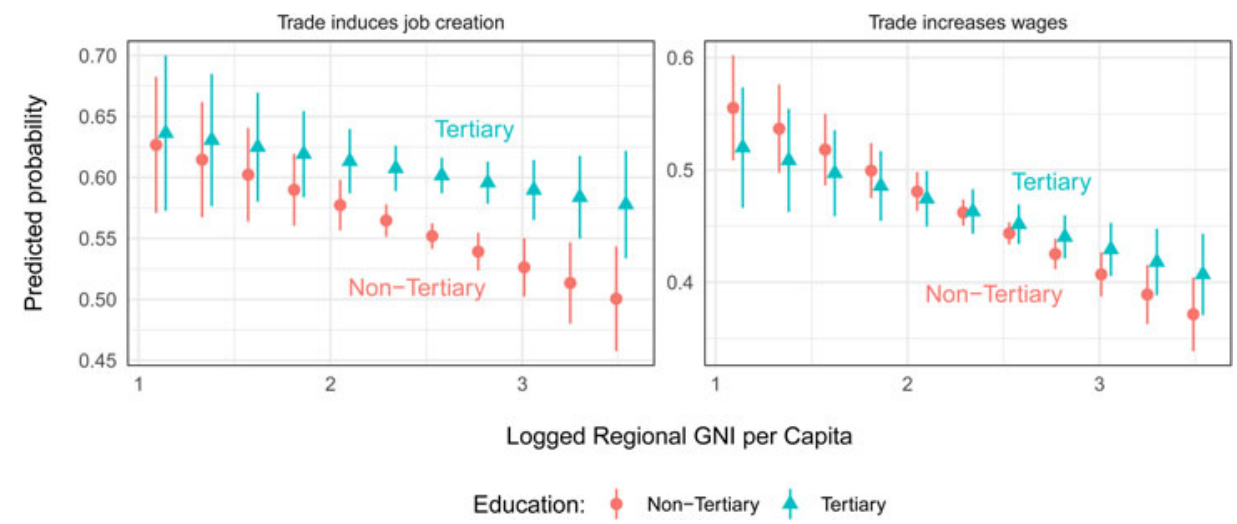

Figure 3. Education, level of development, and perceived consequences of trade

Notes: Predicted values stem from the respective models shown in Table 2. Standard errors are clustered at the region level. Ranges show 90\% confidence intervals. Figures A10 and A11 in the Appendix show the predictions for all outcome categories.

level of trade competitiveness. In other words, whether the region is highly competitive does not alter the perception that trade creates jobs and increases wages (red dotted ranges in Figure 4). In contrast, tertiary educated individuals are more likely to think trade is good in terms of jobs and wages the more competitive the region is. These findings lend support for Hypothesis $4 .^{3}$

An alternative explanation for the interaction between education and the region-level context factors is that higher education is associated with knowledge about these factors that is more factual. In this view, the attitudes of the less-well educated are less influenced by the levels of regional development and regional competitiveness simply because they have little to no information about how developed or competitive their regions are. It seems, however, probable that citizens

\footnotetext{
${ }^{3}$ To see how robust these and the other findings reported here are, we (1) split the education profiles into three groups (primary, secondary, and tertiary education); (2) replaced the age groups with age as a continuous variable; and (3) tested three-way interaction effects between education, employment, and regional development/trade competitiveness. The results are largely in line with those reported here. For more details on these tests, see section A7 in the Appendix.
} 


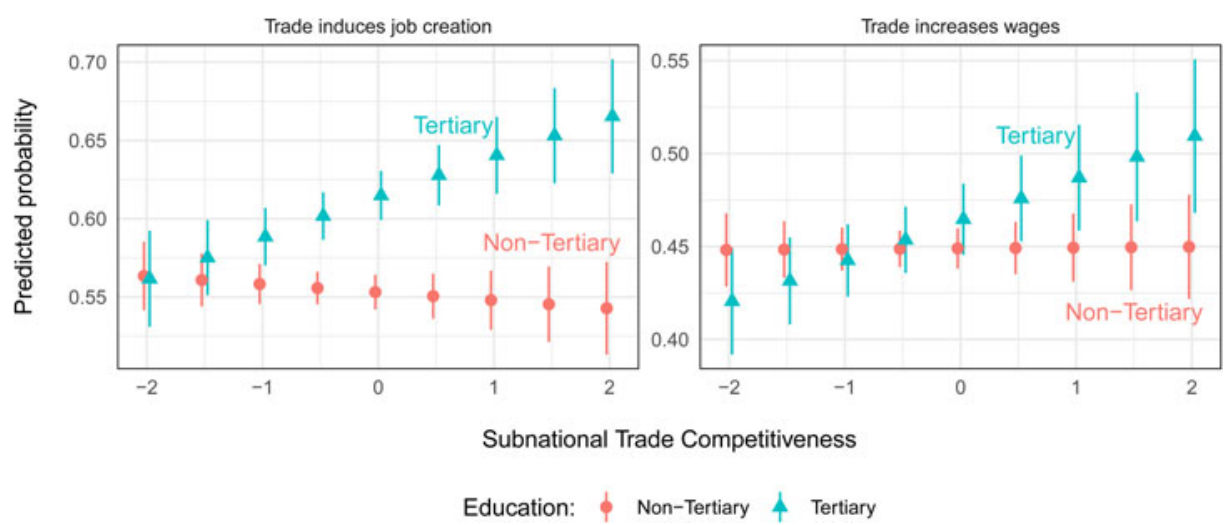

Figure 4. Education, trade competitiveness, and perceived consequences of trade Note: Predicted values stem from the respective models shown in Table 2. Standard errors are clustered at the region level. Ranges show $90 \%$ confidence intervals. Figures A12 and A13 in the Appendix show the predictions for all outcome categories.

across all education groups have at least a broad sense of these context factors Enns and Kellstedt (2008). While we cannot fully exclude this alternative explanation, we thus find it more plausible that our results are driven by citizens reflecting about how the context factors moderate trade's consequences on jobs and wages.

\subsection{From Perceptions of the Consequences of Trade to Trade Support}

To a large extent, the previous analyses have offered support for the expectations set out above. What we have not yet looked at is whether these perceptions of the consequences of trade for jobs and wages matter for attitudes towards trade in general. Following the economic interest approach, we should indeed see that those that perceive trade to have positive consequences also view trade per se positively. To analyze this, we utilize a question in the survey that asked respondents to indicate on a four-point scale whether they think that 'the growing trade and business ties' between their country and other countries are very bad (4.9\%), somewhat bad (11.1\%), somewhat good $(49.0 \%)$, or very good $(35.0 \%)$ for their country.

Utilizing a similar modelling approach and ordinal regression with region-clustered standard errors and country-fixed effects as before, Table A3 in the Appendix shows that the perception of the consequences of trade for jobs and wages indeed matters for individual trade support. As expected, education is positively correlated with trade support in the first model. The controls, particularly economic left-right self-placement and gender, behave as shown in the main models. The second model additionally includes the variables capturing perceptions of trade's consequences. For illustrative purposes, we recoded these variables so that 'does not make a difference' is the reference category. All four variables behave as expected. Individuals who believe trade leads to job loss and lower wages support trade substantially less. In contrast, believing that trade holds positive effects increases trade support substantially.

\section{Conclusion}

This research note has addressed the long-running debate about the empirical observation that the highly educated are more supportive of international trade. Some studies focus on how, at least in developed countries, the highly educated stand to benefit materially from trade liberalization, and hence have an economic reason to support trade (Mayda and Rodrik, 2005). An even larger group of studies, however, argues that education is itself a factor in determining support for 
Table 3. Summary of the findings

\begin{tabular}{llcc}
\hline & Moderator & Hypothesis & Evidence \\
\hline Conditional effect of & Employment status & 1 & Partly supported \\
& Age & 2 & Supported \\
& Regional development & 3 & Supported \\
& Trade competitiveness & 4 & Supported \\
\hline
\end{tabular}

trade liberalization. This may be so because the highly educated are more cosmopolitan (Mansfield and Mutz, 2009) or because university students are taught about the benefits of free trade and thus internalize a love for globalization (Hainmueller and Hiscox, 2006).

With the aim of contributing to this debate, we have proposed four hypotheses derived from the economic interest approach and have exposed them to an empirical test. To the extent that this test supports the hypotheses, we can conclude that the economic interest perspective does retain at least some explanatory power. Indeed, this is what we find (see Table 3). Concretely, our findings suggest that the effect of education on perceptions of the consequences of trade for jobs and wages is larger for employed (H1) and older (H2) respondents, as well as for respondents living in more developed (H3) and economically competitive (H4) regions. We also showed that the perceptions of the consequences of trade matter for attitudes towards trade in general.

Clearly, these tests are not aimed at falsifying the ideational perspective. Existing research has shown that ideas are partly responsible for the positive relationship between education and trade support. Our aim was more modest, namely to see whether there are some aspects of public opinion towards trade that after all are best explained by economic interest. The key take-away hence is that even if the ideational channel plays a role in creating the education-trade support link, it is important not to discard the role of economic interest.

We hope that these findings inspire additional research on trade attitudes. In particular, our findings beg the question as to why respondents' trade attitudes at least partly reflect their economic interests when most people lack concrete knowledge about trade and its distributional consequences (Rho and Tomz, 2017). How does this effect come about? And to which extent does it reflect egoistic or sociotropic considerations on behalf of citizens? Addressing these questions even more thoroughly will require experimental research. Whereas education level itself cannot be manipulated in an experiment, a person's perceptions of how level of education and gains from trade are related most likely can be manipulated.

Moreover, it would be interesting to investigate which individual-level characteristics can explain whether a person's trade attitudes are in line with his or her economic interests. It seems clear that the aggregate results that we present mask much heterogeneity at the individual level about how education matters for trade attitudes. Future research could also scrutinize how education affects the perception of trade's consequences on other issues. For example, how does education influence citizens' perception of the relation between trade and environmental degradation (Nguyen et al., 2021) or social rights (Bastiaens and Postnikov, 2020)? Naturally, these dimensions and perceptions associated with them play a major role in public opposition to trade agreements, such as the EU-Mercosur trade agreement.

Our research also has implications beyond the literature on public opinion towards trade. For one, our findings support the key assumption underlying the Open Economy Politics approach that economic interests matter for individuals' preferences (Lake, 2009). Our findings also speak to the growing literature on the backlash to globalization in developed countries. While future research could investigate the ideational and economic motives to oppose globalization as a whole even more explicitly, our results are at least indicative of the role of economic interest in this backlash. 
Supplementary Materials. To view supplementary material for this article, please visit https://doi.org/10.1017/ S1474745621000562.

Acknowledgements. For comments on earlier versions of this paper, we are grateful to Michael Aklin, Ryan Brutger, Scott Hamilton, Julia Parteymüller, Damian Raess, and audiences at the annual conference of the Swiss Political Science Association in Lucerne, 2020, the Virtual IPES, 2020, the ECPR Annual Conference, 2020, and the annual conference of the Austrian Political Science Association, 2020. This research has received funding from the European Research Council (ERC) under the European Union's Horizon 2020 research and innovation programme (grant agreement No 724107).

\section{References}

Autor, D., D. Dorn, G. Hanson, and K. Majlesi (2020) 'Importing Political Polarization? The Electoral Consequences of Rising Trade Exposure', American Economic Review 110(10), 3139-3183.

Bastiaens, I. and E. Postnikov (2020) 'Social Standards in Trade Agreements and Free Trade Preferences: An Empirical Investigation', The Review of International Organizations 15(4), 793-816.

Bernard, A.B., J. Bradford Jensen, and P.K. Schott (2009) 'Importers, Exporters and Multinationals: A Portrait of Firms in the US that Trade Goods', in T. Dunne, J. Bradford Jensen, and M.J. Roberts (eds.), Producer Dynamics: New Evidence from Micro Data. Chicago: University of Chicago Press, 513-552.

Burgoon, B. and M.J. Hiscox. (2004) 'The Mysterious Case of Female Protectionism: Gender Bias in Attitudes toward International Trade', https://international.ucla.edu/media/files/perg.hiscox.pdf.

Burstein, A. and J. Vogel (2017) 'International Trade, Technology, and the Skill Premium', Journal of Political Economy 125 (5), 1356-1412.

Campello, D. and F. Urdinez (2021) 'Voter and Legislator Responses to Localized Trade Shocks from China in Brazil', Comparative Political Studies 54(7), 1131-1162.

Carreras, M., Y.I. Carreras, and S. Bowler (2019) 'Long-Term Economic Distress, Cultural Backlash, and Support for Brexit', Comparative Political Studies, doi:10.1177/0010414019830714.

Ciuriak, D., B. Lapham, R. Wolfe, T. Collins-Williams, and J. Curtis (2015) 'Firms in International Trade: Trade Policy Implications of the New New Trade Theory', Global Policy 6(2), 130-140.

Coenders, M. and P. Scheepers (2003) 'The Effect of Education on Nationalism and Ethnic Exclusionism: An International Comparison', Political Psychology 24(2), 313-343.

Department for International Trade. (2019) 'Public Attitudes to Trade Tracker Wave One Report.

Enns, P.K. and P.M. Kellstedt (2008) 'Policy Mood and Political Sophistication: Why Everybody Moves Mood', British Journal of Political Science 38(03), 433-454.

Fordham, B.O. and K.B. Kleinberg (2012) 'How Can Economic Interests Influence Support for Free Trade?', International Organization 66(2), 311-328.

Hafner-Burton, E.M., S. Haggard, D.A. Lake, and D.G. Victor (2017) 'The Behavioral Revolution and International Relations', International Organization 71(S1), S1-S31.

Hainmueller, J. and M.J. Hiscox (2006) 'Learning to Love Globalization: Education and Individual Attitudes Toward International Trade', International Organization 60(02), 469-498.

Helpman, E., O. Itskhoki, M.-A. Muendler, and S.J. Redding (2017) 'Trade and Inequality: From Theory to Estimation', The Review of Economic Studies 84(1), 357-405.

Huber, R.A., Y. Stiller, and A. Dür (2021) 'Measuring Subnational Trade Competitiveness', Preprint Open Science Framework, https://osf.io/au754.

Kaltenthaler, K.C., R.D. Gelleny, and S.J. Ceccoli (2004) 'Explaining Citizen Support for Trade Liberalization', International Studies Quarterly 48(4), 829-851.

Kono, D.Y. (2008) 'Does Public Opinion Affect Trade Policy?', Business and Politics 10(2), 1-19.

Lake, D.A. (2009) 'Open Economy Politics: A Critical Review', Review of International Organizations 4(3), $219-244$.

Lee, E. (2020) 'Trade, Inequality, and the Endogenous Sorting of Heterogeneous Workers', Journal of International Economics, Elsevier, vol. 125(C).

Mansfield, E.D. and D.C. Mutz (2009) 'Support for Free Trade: Self-Interest, Sociotropic Politics, and Out-Group Anxiety', International Organization 63(3), 425-457.

Mansfield, E.D., D.C. Mutz, and L.R. Silver (2015) 'Men, Women, Trade, and Free Markets', International Studies Quarterly 59(2), 303-315.

Margalit, Y. (2012) 'Lost in Globalization: International Economic Integration and the Sources of Popular Discontent', International Studies Quarterly 56(3), 484-500.

Mayda, A.M. and D. Rodrik (2005) 'Why are some people (and countries) more protectionist than others?', European Economic Review 49(6), 1393-1430.

Melitz, M.J. (2003) 'The Impact of Trade on Intra-Industry Reallocations and Aggregate Industry Productivity', Econometrica 71(6), 1695-1725. 
Nguyen, Q., R.A. Huber, and T. Bernauer (2021) 'Environmental Impacts and Public Opinion About International Trade: Experimental Evidence from Six OECD Countries', Global Environmental Politics, 21(3), 49-76.

Oatley, T. (2011) 'The Reductionist Gamble: Open Economy Politics in the Global Economy', International Organization 65 (2), 311-41.

O'Rourke, K.H. and R. Sinnott (2001) 'The Determinants of Individual Trade Policy Preferences: International Survey Evidence', in S.M. Collins and D. Rodrik (eds.), Brookings Trade Forum. Washhington, DC: Brookings Institution Press, pp. 157-186.

Pew Research Center. (2014) 'Global Attitudes \& Trends. Spring 2014 44-Nation Survey.

Rho, S. and M. Tomz (2017) 'Why Don’t Trade Preferences Reflect Economic Self-Interest?', International Organization 71 (S1), S85-S108.

Schaffer, L.M. and G. Spilker (2019) 'Self-Interest versus Sociotropic Considerations: An Information-Based Perspective to Understanding Individuals' Trade Preferences', Review of International Political Economy 26(6), 1266-1292.

Scheve, K.F. and M.J. Slaughter (2001) 'What determines individual trade-policy preferences?', Journal of International Economics 54(2), 267-292.

Smits, J. and I. Permanyer (2019) 'The Subnational Human Development Database', Scientific Data 6(1), 190038.

Strijbis, O., C. Teney, and M. Helbling (2019) 'Why Are Elites More Cosmopolitan than Masses?', in M. Zürn, O. Strijbis, P. de Wilde, R. Koopmans, and W. Merkel (eds.), The Struggle Over Borders: Cosmopolitanism and Communitarianism. Cambridge: Cambridge University Press, 37-64.

van der Waal, J. and W. de Koster (2015) 'Why Do the Less Educated Oppose Trade Openness? A Test of Three Explanations in the Netherlands', European Journal of Cultural and Political Sociology 2(3-4), 313-344.

Vollrath, T.L. (1991) 'A Theoretical Evaluation of Alternative Trade Intensity Measures of Revealed Comparative Advantage', Weltwirtschaftliches Archiv 127(2), 265-280.

Cite this article: Stiller Y, Dür A, Huber RA (2022). Education and Trade Attitudes: Revisiting the Role of Economic Interest. World Trade Review 21, 497-511. https://doi.org/10.1017/S1474745621000562 